\section{BCG in cancer}

Like that of any other disease, the management of cancer requires a logical approach. Unfortunately much of the immunotherapy of malignant disease has escaped this dictum, since the wilder concepts were already in vogue early in this century. The rationale for immunotherapy had to await the identification of tumour-specific antigens in transplantable tumours in syngeneic animal populations. ${ }^{1-3}$ Although the protective effects of immunising these animals against their own tumours has been shown time and again, the application of these findings to tumours arising spontaneously in animals and man is far less clear. In such cases investigations have failed to show tumour-specific antigens; and their existence would be irrelevant to treatment if once identified they proved to be non-immunogenic. Nevertheless, specific active immunotherapy has been often given on the presumption that such antigens do exist. Frequently this has been combined with BCG in the belief that this gives a non-specific boost to the specific anti-tumour response. Just how useful the specific immune response is in terms of treatment is difficult to assess, but many studies now suggest that some benefit is attributable to the activity of BCG.

Bacterial toxins have been used in treating cancer for many years with sporadic success. ${ }^{4}$ BCG was found to have a potent immuno-stimulatory effect on responses to heterologous antigens $^{5-7}$ and is known to evoke a wide range of changes in the host. These include non-specific stimulation of activity of the reticuloendothelial system ${ }^{8}$-and a concomitant increase in the numbers of macrophages in the spleen, liver, and lungs"; localised changes in tissue at the site of injection ${ }^{10}$; activation of macrophages ${ }^{11}$; release of interferon ${ }^{12}$; increased phagocytosis; and enhanced homograft rejection. ${ }^{13}$

Many workers have found that direct injection of BCG into established tumours may cause regression of tumours and elimination of tumour cells from regional lymph nodes, while injection at a distant site is far less effective. Animal studies of the latter have shown enhancement, reduction, or no change in growth after injection of BCG. It has been presumed that when there is minimal residual disease inoculating BCG may lead to increased tumour-directed immune reactivity. If a tumour-specific immune response exists, this may exert a controlling effect on the tumour-but immune manipulation may also facilitate its growth.

The relevance of an intact immune response to therapeutic benefit in malignant disease treated with BCG is not yet clear. Nevertheless, nearly all responses in patients treated in this way have occurred where crudely tested delayed hypersensitivity mechanisms have been intact. The crucial question seems to be whether tumour-specific antigens are present, important, or even relevant to the response seen after treatment with BCG. A recent review ${ }^{14}$ has suggested that for BCG to be effective there must be few tumour cells; the host must be able to develop an immune response to microbial antigens; and adequate numbers of BCG organisms must be injectedand that these are most effective when closely associated with the tumour cells. Whether or not tumour cells need to be immunogenic is still not clear. ${ }^{15-17}$

Animal studies have shown that pretreatment with BCG may delay the appearance of tumours induced by carcinogens and viruses. Once the tumours have developed its influence on growth is variable. A comparable variation may exist in man: possibly BCG vaccination in childhood may reduce the incidence of acute leukaemia. ${ }^{18}$ Other reports present conflicting interpretations, however, so that we do not know whether vaccination in childhood with BCG does in fact reduce the risk of mortality from acute leukaemia. Again, while immunotherapy with BCG or with BCG together with allogeneic leukaemic cells was reported to prolong disease-free survival in patients in remission from acute lymphoblastic leukaemia, ${ }^{19}$ subsequent trials have failed to substantiate this. In acute myelogenous leukaemia various trials suggest that survival may be prolonged. ${ }^{20} 21$

Probably one of the most important effects of BCG is to activate macrophages non-specifically. There is now good evidence of non-immunologic recognition and destruction of malignant cells by activated macrophages, while normal contact-inhibited cells remain undamaged. ${ }^{22}$ Meanwhile the relative harmlessness of $\mathrm{BCG}$, its ready availability, and its theoretical capability for potentiating the host's antitumour response have encouraged its widespread and uncritical use. Recent reports ${ }^{2324}$ have added to an ever-growing number of studies in which BCG given regionally was cast in the crucial role of scavenger of minimal residual disease. Nevertheless, if the potential benefits of BCG used in malignant disease are to be fully realised, further carefully controlled trials must be carried out in conjunction with laboratory studies aimed at elucidating the mechanisms by which it might act.

${ }^{1}$ Gross, L, Cancer Research, 1943, 3, 326.

2 Foley, E J, Cancer Research, 1853, 13, 835.

${ }^{3}$ Prehn, R T, and Main, J M, Fournal of the National Cancer Institute, 1957, 18, 769.

4 Nauts, H C, New York Cancer Research Institute Monograph 8, 1969.

5 Lewis, P A, and Loomis, D, Journal of Experimental Medicine, 1924, 40, 503.

${ }^{6}$ Dienes, L, and Schoenheit, E W, fournal of Immunology, 1930, 19, 41.

' Freund, J, Advances in Tuberculosis Research, 1965, 7, 130.

Weiss, D W, Nature, 1960, 186, 1060.

${ }^{9}$ Biozzi, G, et al, Annales de l'Institut Pasteur, 1954, 87, 291.

${ }^{10}$ Alexander, P, National Cancer Institute, Monographs 1973, 39, 127.

${ }^{11}$ Evans, R, and Alexander, P, Nature, 1972, 236, 168.

12. Salvin, S B, Youngner, J S, and Lederer, W H, Infection and Immunity, 1973, 7, 68.

${ }^{13}$ Balner, H, Old, L J, and Clarke, D A, Proceedings of the Society for Experimental Brology and Medicine, 1962, 109, 58.

${ }^{14}$ Bast, R C, et al, New England fournal of Medicine, 1974, 290, 1413.

${ }^{15}$ Baldwin, R W, and Pimm, M V, British Fournal of Cancer, 1973, 27, 48.

${ }^{16}$ Parr, I, British Fournal of Cancer, 1972, 26, 174.

17 Bartlett, G L, and Zbar, B, Fournal of the National Cancer Institute, 1972, 48, 1709.

18 Davignon, L, et al, Lancet, 1970, 2, 638.

19 Mathé, G, British Medical fournal, 1969, 4, 7.

20 Powles, R L, et al, British fournal of Cancer, 1973, 28, 365.

21 Gutterman, J U, et al, Lancet, 1974, 2, 1405.

2:2 Hibbs, J B, Science, 1973, 180, 868.

2:3 Eilber, F R, et al, New England Fournal of Medicine, 1976, 294, 237.

${ }^{24}$ McKneally, M F, Maver, C, and Kausel, H W, Lancet, 1976, 1, 377.

\section{Cerebral blood flow in dementia}

Not long after the nitrous oxide method of measuring blood flow through the cerebral hemisphere $(\mathrm{CBF})$ was introduced by Kety and Schmidt in $1945^{1}$ reports ${ }^{2-4}$ began to appear of reduced flow in patients with organic dementia. Interest in the subject then waned until recently, when the facility for measuring regional cerebral blood flow by injection of isotopes into the internal carotid artery ${ }^{5}$ and the finding that focal increase in regional flow could be related to specific neurological and psychological activity stimulated new research. There was shown to be a focal increase in blood flow over the motor cortex during exercise of the contralateral $\mathrm{arm}^{6}{ }^{6}$ and a general 